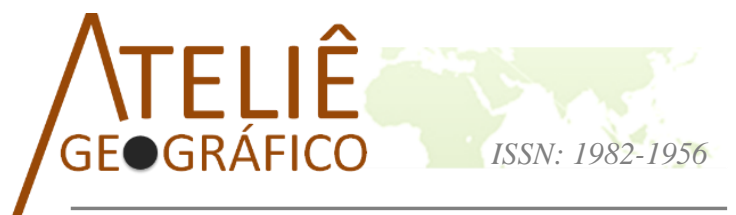 \\ http://www.revistas.ufg.br/index.php/atelie
}

\section{Suscetibilidade biofísica a inundações da Sub-bacia Hidrográfica do rio Piracuruca}

\author{
Biophysical susceptibility to flooding in the Piracuruca \\ River Hydrographic Sub-basin
}

\section{Susceptibilidad biofísica a las inundaciones en la Subcuenca Hidrográfica del río Piracuruca}

\author{
Francílio de Amorim dos Santos \\ Instituto Federal do Piauí / Campus Piripiri \\ francilio.amorim@ifpi.edu.br \\ Lúcia Maria Silveira Mendes \\ Universidade Estadual do Ceará \\ lucia.mendes@uece.br \\ Maria Lúcia Brito da Cruz \\ Universidade Estadual do Ceará \\ mlbcruz@gmail.com
}

\begin{abstract}
Resumo
O estudo objetivou realizar avaliação da suscetibilidade biofísica a inundações da Subbacia Hidrográfica do rio Piracuruca, a partir de quatro indicadores ambientais permeabilidade litológica, declividade média do relevo, índice de circularidade e índice de vegetação ajustado ao solo (SAVI) - que foram integrados por meio de álgebras de mapas. A pesquisa empregou levantamento bibliográfico e cartográfico, uso de Sistemas de Informação Geográfica e álgebra de mapas para construção do índice de suscetibilidade biofísica a inundações. Através do estudo inferiu-se que na Sub-bacia do rio Piracuruca prevalece: permeabilidade alta, que ocorre em $58,8 \%$ de sua área; relevo com declividade plana em 58,4\%; microbacias com forma alongada e índice de circularidade geral $\leq 0,35$, que representa baixa probabilidade a inundações rápidas; vegetação com baixa atividade fotossintética identificada em $49 \%$ da área. Essas variáveis integradas apontam que predomina média suscetibilidade biofísica a inundações, com ocorrência em 59,5\% da Sub-bacia, que indica necessidade de estudos posteriores para conhecimento da vulnerabilidade da população situada e criação de estratégias para convivência com as inundações.
\end{abstract}

Palavras-chave: Bacia Hidrográfica; Desastre Natural; Álgebra de mapas; Suscetibilidade biofísica. 


\begin{abstract}
The study aimed to evaluate the biophysical susceptibility to flooding of the Piracuruca River Hydrographic Sub-basin, based on four environmental indicators - lithological permeability, average relief gradient, circularity index and vegetation index adjusted to the soil (SAVI) - which have been integrated using map algebras. The research employed bibliographic and cartographic survey, use of Geographic Information Systems and map algebra to build the biophysical susceptibility index to floods. Through the study it was inferred that in the Piracuruca River Sub-basin the following prevails: high permeability, which occurs in $58.8 \%$ of its area; relief with a flat slope of $58.4 \%$; micro basins with elongated shape and general circularity index $\leq 0.35$, which represents a low probability of rapid flooding; vegetation with low photosynthetic activity was identified in $49 \%$ of the area. These integrated variables indicate that the average biophysical susceptibility to floods predominates, occurring in $59.5 \%$ of the Sub-basin, which indicates the need for further studies to understand the vulnerability of the located population and the creation of strategies to cope with floods.
\end{abstract}

Keywords: Hydrographic Basin; Natural Disaster; Map Algebra; Biophysical Susceptibility.

\begin{abstract}
Resumen
El estudio tuvo como objetivo evaluar la susceptibilidad biofísica a las inundaciones de la Subcuenca Hidrográfica del río Piracuruca, en base a cuatro indicadores ambientales - permeabilidad litológica, gradiente de alivio promedio, índice de circularidad y índice de vegetación ajustado al suelo (SAVI) - que se han integrado por medio de álgebras de mapas. La investigación empleó encuestas bibliográficas y cartográficas, uso de Sistemas de Información Geográfica y álgebra de mapas para construir el índice de susceptibilidad biofísica a las inundaciones. A través del estudio se infirió que en la Subcuenca del río Piracuruca prevalece lo siguiente: alta permeabilidad, que ocurre en $58.8 \%$ de su área; relieve con una pediente plana de $58.4 \%$; microcuencas con forma alargada e índice de circularidad general $\leq 0.35$, lo que representa una baja probabilidad de inundación rápida; vegetación con baja actividad fotosintética identificada en el $49 \%$ del área. Estas variables integradas indican que predomina la susceptibilidad biofísica promedio a las inundaciones, que ocurre en el 59.5\% de la Subcuenca, lo que indica la necesidad de más estudios para comprender la vulnerabilidad de la población localizada y la creación de estrategias para hacer frente a las inundaciones.
\end{abstract}

Palabras clave: Cuenca hidrográfica; Desastre natural; Álgebra de mapas; Biofísica Susceptibilidad.

\title{
Introdução
}

O Nordeste do Brasil (NEB) constitui uma região de singulares características geoambientais, particularmente destacando-se as condições climáticas da área semiárida. Nessa ressaltam-se os totais pluviométricos, que se concentram em curto período de tempo e estão associados à atuação da Zona de Convergência Intertropical (ZCIT), principal sistema provedor de chuvas para o setor Norte do NEB.

Embora outros sistemas atmosféricos atuem no NEB, a ZCIT é aquela responsável pela delimitação do período chuvoso. Esse sistema tem sua intensidade e posicionamento ligado à ocorrência de dois fenômenos oceânicos o El Niño Oscilação Sul 
(ENOS) e a diferença na temperatura do Atlântico Norte e do Atlântico Sul, o dipolo do Atlântico, que geram anos normais ou anômalos.

A ZCIT diz respeito a uma área de alta instabilidade, onde os ventos alísios convergentes ascendem a camadas superiores da atmosfera e resultam numa faixa de nuvens facilmente identificável em imagens de satélites, movimenta-se durante o verão para o hemisfério norte ou para o hemisfério sul (AYOADE, 2001; XAVIER, 2001). De modo específico, ressalta-se que a ZCIT move-se de sua posição mais setentrional, aproximadamente $12^{\circ} \mathrm{N}$, em agosto-setembro, para sua posição mais meridional, aproximadamente $4^{\circ} \mathrm{S}$, em março-abril (FUNCEME, 2019a).

Por sua vez, de acordo com Molion e Bernardo (2000) e Ferreira e Mello (2005), o ENOS está associado a uma perturbação climática de escala global que está ligado às águas superficiais do oceano Pacífico, em torno do Equador. Nesse estudo dar-se-á ênfase à fase fria do ENOS, o La niña, que está ligada às temperaturas muito abaixo do normal nas águas da parte tropical oeste do Pacífico, que apresenta pressão ao nível do mar mais baixa que a média climatológica e favorece a convecção, a nebulosidade e a precipitação (XAVIER, 2001; VAREJÃO-SILVA, 2006).

Por seu turno, a diferença de gradiente entre a temperatura da superfície do mar (TSM) entre as bacias norte e sul do oceano Atlântico, dipolo do Atlântico, cuja linha de separação dessas duas bacias é delimitada pelo paralelo $5^{\circ} \mathrm{N}$ (FUNCEME, 2019b). Ferreira e Mello (2005) destacam que essa diferença de temperatura da TSM nas bacias do Atlântico Norte e Sul perturba as células de Hadley e de Walker, gerando fortes anomalias na circulação atmosférica sobre os trópicos. Nesse cenário, destaca-se que quando a TSM do Atlântico norte encontra-se mais fria que a do Atlântico sul, resulta na intensificação do Sistema de Alta Pressão do Atlântico Norte (AAN) e dos ventos ANE, possibilitando o deslocamento da ZCIT para sua posição mais meridional.

Em anos que ocorre La niña e/ou dipolo positivo do Atlântico ocasionam-se anomalias pluviométricas positivas, ou seja, a ZCIT desce a sua posição mais ao sul e gera totais pluviométricos acima da média histórica, tendo como principal consequência o desastre natural hidrológico denominado inundação. De acordo com o Anuário Brasileiro de Desastres Naturais, os desastres naturais são produto "[...] de eventos adversos, naturais ou provocados pelo homem, sobre um cenário vulnerável, causando grave perturbação ao funcionamento de uma comunidade ou sociedade, envolvendo extensivas perdas e danos humanos, materiais, econômicos ou ambientais, que excede a sua capacidade de lidar com o problema usando meios próprios" (BRASIL, 2014, p.15).

As inundações, por sua vez, constituem desastres naturais hidrológicos que ocorrem com periodicidade nos cursos d'água e são frutos de chuvas fortes e rápidas ou de longa duração (TOMINAGA; SANTORO; AMARAL, 2009). Nesse cenário, Monteiro e Pinheiro (2012) afirmam que as populações urbanas são mais atingidas pelos efeitos das anomalias pluviométricas positivas, ao passo que Silva, Paiva e Santos (2015) asseveram que o desenvolvimento das cidades tem dificultado as condições de escoamento 
superficial, que representa um gerador de alagamentos e inundações nas áreas urbanas, deixando vítimas e diversos prejuízos sociais e econômicos.

Desse modo, constitui de grande relevância a realização de estudos em bacias hidrográficas, que, de acordo com Pinheiro (2011), apresenta caráter sistêmico devido ser um sistema aberto e está sujeito a entrada e saída de energia e matéria. Cardoso (2013), por sua vez, aponta que há interdependência entre os componentes que constituem a bacia hidrográfica, logo, aponta que esse recorte espacial representa a um sistema não isolado aberto. Dessa forma, destaca-se que o estudo será realizado na Sub-bacia Hidrográfica do rio Piracuruca, situada entre os estados do Ceará e do Piauí, no Norte do Nordeste do Brasil.

Nesse sentido, associado à bacia hidrográfica tomou-se como base a abordagem sistêmica como método de integração. Camargo (2012, p.34) considera o sistema como "[...] um elemento que, em virtude de sua interação interna e externa (com outros sistemas), evolui diacronicamente, [...] é uma totalidade que entra em totalização constante na busca do equilíbrio ou da ordem". Nesse sentindo, para a realização do estudo foi necessário a aquisição de dados vetoriais e matriciais junto ao banco de dados de diversos órgãos governamentais.

Esses dados foram manuseados e refinados no Sistema de Informação Geográfica (SIG) ArcGIS, versão 10.2 (licença adquirida pela Universidade Federal do Piauí), SPRING, versão 5.1, e QGIS, versão 2.14, particularmente para emprego da álgebra de mapas e produção do layout final dos mapas. Dessa forma, foi possível ter conhecimento da suscetibilidade a inundações da Sub-bacia pesquisada.

Deve-se entender suscetibilidade como um conjunto de fatores naturais que o terreno apresenta e que determinam seu potencial para deflagração de determinados desastres (LISTO, 2011). Desse modo, destaca-se que o estudo propôs-se a realizar avaliação da suscetibilidade biofísica a inundações da Sub-bacia Hidrográfica do rio Piracuruca, a partir de quatro indicadores ambientais - permeabilidade litológica, declividade média do relevo, índice de circularidade e índice de vegetação ajustado ao solo - que foram integrados por meio de álgebras de mapas.

\section{Metodologia}

\section{Localização e caracterização ambiental da área em estudo}

A pesquisa considerou como recorte espacial a Sub-bacia Hidrográfica do rio Piracuruca, que está localizada entre os estados do Ceará e do Piauí, no Nordeste do Brasil (Figura 1), compreendendo uma área de 7.704,0 $\mathrm{km}^{2}$. Ressalta-se que o rio principal da Sub-bacia nasce em território cearense, no Planalto da Ibiapaba, e corre no sentido Sudeste, sob o nome de Arabé, e ao adentrar ao município de Piracuruca (Piauí) recebe a denominação o dito município, vindo a desaguar no rio Longá, a altura do município de São José do Divino. 
Ressalta-se que a Sub-bacia em questão compreende áreas de 20 municípios, sendo onze deles localizados em território piauiense e nove no estado do Ceará. Ao passo que desses vinte municípios oito deles têm suas sedes inseridas nos limites da Sub-bacia, sendo cinco piauienses e três cearenses. As principais vias de acesso às sedes desses oito municípios são as seguintes: BR-343, sentido Teresina a Parnaíba; a BR-222, sentido Teresina a Tianguá; a PI-110, que liga Piracuruca (PI) a BR-222; PI-258, que liga Domingos Mourão a BR-222; a CE-187, que passa pelos municípios cearenses de Ubajara, Ibiapina e São Benedito.

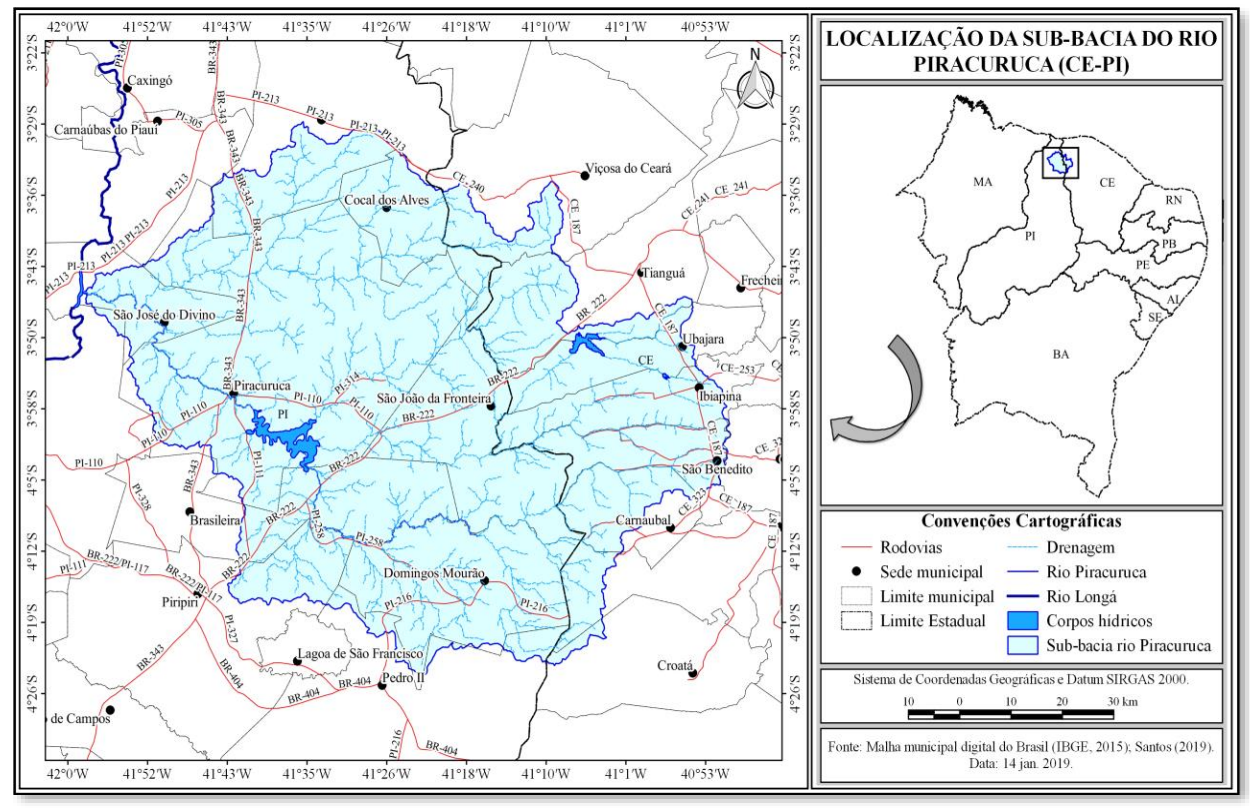

Figura 1: Localização da Sub-bacia Hidrográfica do rio Piracuruca, situada na divisa dos estados do Ceará e do Piauí, Nordeste do Brasil.

Litologicamente, a Sub-bacia pesquisada está assentada sobre formações de natureza predominantemente sedimentar, com exceção de uma, como se segue: Grupo Serra Grande (Período Siluriano); Formação Pimenteiras (Período Devoniano Inferior); Formação Cabeças (Período Devoniano Médio); Formação Sardinha (Período Cretáceo, única de origem vulcânica); Depósitos Colúvio-Eluviais (Período Neógeno) (CPRM, 2006a; 2006b; 2006c). Ressalta-se que essas formações se encontram em processo de desgaste devido, entre outros processos, a atuação da rede drenagem consequente.

Do ponto de vista climático, a áreas apresenta influência dos seguintes sistemas atmosféricos (FERREIRA; MELLO, 2005): Zona de Convergência Intertropical (ZCIT), principal sistema provedor de chuvas; Vórtices Ciclônicos de Altos Níveis (VCANs); Distúrbios Ondulatórios de Leste (DOL); Linhas de Instabilidade (LIs); Perturbações Ondulatórias nos Alísios (POA). 
Convém destacar que o posicionamento da ZCIT e respectivos anos normais ou anômalos está bastante associado aos fenômenos oceânicos El Niño Oscilação Sul (ENOS) e Dipolo do Atlântico. Nesse contexto, o estudo de Santos (2019) apontou que ocorrem na área as seguintes características climáticas: precipitações que variam de 860 a $1.710 \mathrm{~mm}$ anuais; temperaturas que oscilam de 20 a $27^{\circ} \mathrm{C}$; até sete meses secos; evapotranspiração potencial de 903 a $1643 \mathrm{~mm}$; excedente hídrico de 100 a $1.000 \mathrm{~mm}$ e déficits da ordem de 30 a $730 \mathrm{~mm}$ anuais.

$\mathrm{Na}$ área da Sub-bacia encontra-se um mosaico com onze subordens de solos, quais sejam: Argissolo Amarelo, Argissolo Vermelho, Chernossolo Argilúvico, Gleissolo Melânico, Latossolo Amarelo, Neossolo Litólicos, Neossolo Quartzarênico, Planossolo Háplico, Plintossolo Argilúvico, Plintossolo Pétrico, Vertissolo Ebânico (INDE, 2014). As referidas subordens de solos associadas às condições climáticas e do relevo possibilitam o desenvolvimento de distintas fisionomias de cobertura vegetal, onde no platô do Planalto tem-se a mata plúvio-nebular, que ocorre em solos mais profundos e maduros. Enquanto em direção ao estado do Piauí essa cobertura vegetal tem seu porte reduzido devido às condições edáficas, passando de mata seca à caatinga arbórea, no platô e na região centro-oeste da Sub-bacia, e caatinga arbustiva nas regiões mais rebaixadas e de maior rigor climático (SANTOS, 2019).

\section{Procedimentos metodológicos}

O estudo constitui uma pesquisa de natureza descritiva, posto que tenha considerado variáveis ambientais para análise e integração cujo foco foi à compreensão da suscetibilidade biofísica a inundações da Sub-bacia Hidrográfica do rio Piracuruca. Ressalta-se que foi realizado levantamento bibliográfico para subsidiar a discussão dos principais conceitos utilizados no estudo.

Como perspectiva para realização da caracterização ambiental e construção do índice de suscetibilidade biofísica a inundações, foi necessária a aquisição de arquivos vetoriais e matriciais junto ao banco de dados de diversos órgãos governamentais. Posteriormente, foi montado um banco de dados, para manuseio e refinamento dos arquivos, mencionados, nos seguintes Sistemas de Informação Geográfica (SIGs): QGIS, versão 2.14; ArcGIS, versão 10.2 (licença adquirida pela Universidade Federal do Piauí); SPRING, versão 5.1 .

De posse dos referidos dados foi empregada álgebras de mapas, onde se utilizou a soma como operador aritmético, para integração das quatro variáveis ambientais permeabilidade litológica, declividade média do relevo, índice de circularidade e índice de vegetação ajustado ao solo (SAVI) - via Equação 1.

$$
I S \text { Bio }_{I}=L+D m+I c+S A V I
$$


Onde:

$$
\begin{gathered}
I S B i o_{I}=\text { Índice de Suscetibilidade Biofísica a Inundações; } \\
L=\text { Permeabilidade litológica; } \\
\text { Dm = Declividade média do relevo; } \\
I c=\text { Índice de circularidade; } \\
S A V I=\text { Índice de vegetação ajustado ao solo. }
\end{gathered}
$$

Na sequência, foi possível realizar procedimento para classificação do ISBio I por meio da opção graduado e método intervalo igual no QGIS. Dessa operação, resultou a delimitação de cinco classes para o ISBioı, conforme pode ser observado na Tabela 1.

Tabela 1: Intervalos, classes atribuídas e notas do ISBio da Sub-bacia Hidrográfica do rio Piracuruca.

\begin{tabular}{c|c|c}
\hline Intervalos de ISBioI & Classes atribuídas & Notas \\
\hline 4,0 a 6,2 & Muito baixa & 2 \\
\hline 6,2 a 8,4 & Baixa & 3 \\
\hline 8,4 a 10,6 & Média & 4 \\
\hline 10,6 a 12,8 & Alta & 5 \\
\hline 12,8 a 15,0 & Muito alta & \\
\hline
\end{tabular}

Fonte: Elaborada pelos autores (2020).

Diante do exposto, é importante detalhar que foram adquiridos vários arquivos vetoriais e matriciais junto ao banco de dados de diversos órgãos governamentais. Dessa foram, a seguir serão mais bem detalhados os procedimentos empregados para o manuseio, refinamento e geração dos produtos finais para cada indicador ambiental utilizado para a construção do ISBioI.

Permeabilidade litológica (L)

Esse indicador litológico permitiu verificar a capacidade de infiltração da Subbacia e demandou aquisição de arquivos vetoriais do mapa da geodiversidade do estado do Piauí e do Ceará (CPRM, 2006b; 2006c). Para classificação da permeabilidade 
litológica da área em estudo foi utilizada a proposta metodológica de Crepani et al. (2001), onde foram delimitadas três classes (Tabela 2).

Tabela 2: Tipos de rochas, classes atribuídas e notas de permeabilidade litológica (L).

\begin{tabular}{c|c|c}
\hline Tipo de rochas & Classes atribuídas & Notas \\
\hline Basaltos, diabásios & Baixa & 2 \\
\hline Arenitos, folhelho e siltito & Média & 3 \\
\hline $\begin{array}{c}\text { Arenito, Conglomerado suportado por Matriz, } \\
\text { Folhelho, Siltito Arenoso }\end{array}$ & Alta & 4 \\
\hline Areia, argila, cascalho & Muito alta & 5 \\
\hline
\end{tabular}

Fonte: Crepani et al. (2001). Adaptado por Santos (2019).

Declividade média do relevo $(\mathrm{Dm})$

Esse indicador, ligado ao relevo, demandou aquisição de arquivo matricial referente aos Modelos Digitais de Elevação (MDEs), da Missão Topográfica Radar Shuttle (SRTM), via banco de dados do Serviço Geológico dos Estados Unidos (USGS, 2019a). De posse desse material, foi empregada a delimitação proposta no Manual Técnico de Geomorfologia (EMBRAPA, 2009), para delimitação dos intervalos das classes de declividade média do relevo (Dm), de acordo com Tabela 3.

Tabela 3. Intervalos, classes atribuídas e notas de declividade média do relevo (Dm) da Sub-bacia Hidrográfica do rio Piracuruca.

\begin{tabular}{c|c|c}
\hline Intervalos de Dm (\%) & Classes atribuídas & Notas \\
\hline 0 a 3 & Plano & 5 \\
\hline 3 a 8 & Suave Ondulado & 4 \\
\hline 8 a 20 & Ondulado & 3 \\
\hline 20 a 45 & Forte Ondulado & 2 \\
\hline 45 a 75 & Montanhoso & 1 \\
\hline
\end{tabular}

Fonte: EMBRAPA (2009). Adaptada pelos autores (2020).

Índice de circularidade (Ic)

Ainda, considerando o elemento geomorfológico, foi empregado o índice de circularidade (Ic) para avaliação da probabilidade das Microbacias (MB) que compõe a Sub-bacia do Rio Piracuruca à ocorrência de inundações. Ressalta-se que foi utilizado os 
arquivo matriciais obtidos via USGS (2019a), cuja delimitação da área das MB foi realizada no SIG ArcGIS, considerando as rotinas expostas na Figura 2.

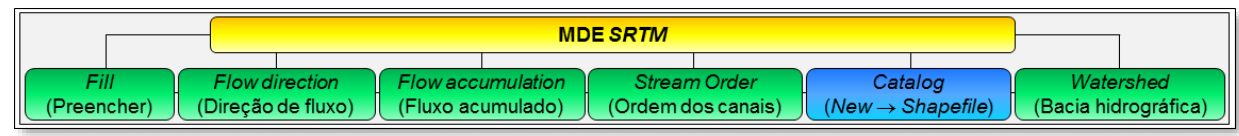

Figura 2: Rotinas pertencentes à extensão Spatial Analyst Tools e ferramenta Hydrology, do SIG AcrGIS.

Fonte: organizado pelos autores (2020).

A realização das rotinas, acima, permitiu a delimitação de cinco Microbacias, que, posteriormente, possibilitaram o emprego da Equação 2, ligada ao Ic, onde se relaciona a área e o perímetro da bacia. Desse modo, quanto mais próximo a 1 for o resultado da equação mais arredondada será a bacia e, como tal, mais sujeita à ocorrência de inundações.

$$
\text { Ic }=12,57 \frac{A}{p^{2}}
$$

Onde:

$$
\begin{gathered}
A=\text { área da bacia em } \mathrm{km}^{2} ; \\
p=\text { perímetro da bacia em } \mathrm{km}^{2} .
\end{gathered}
$$

Após a obtenção dos dados de Ic, foi possível realizar a classificação das MB quanto a sua probabilidade a inundações, de acordo com a proposta metodológica de Schumm (1956), como se pode observar na Tabela 4.

Tabela 4: Intervalos, classes atribuídas e notas ao índice de circularidade (Ic).

\begin{tabular}{c|c|c}
\hline Intervalos de Ic & Classes atribuídas & Notas \\
\hline$<0,51$ & Baixa & 1 \\
\hline 0,51 & Média & 2 \\
\hline$>0,51$ & Alta & 3 \\
\hline
\end{tabular}

Fonte: Schumm (1956). 
Índice de vegetação ajustado ao solo (SAVI)

Para realização do SAVI, inicialmente, foram adquiridas imagens do satélite Landsat 8 OLI, com resolução espacial de $30 \mathrm{~m}$, através do banco de dados USGS (2019b). Essas imagens possuem as seguintes características: órbita/ponto 219/62 e 219/63 e data de passagem de 08/08/2016; órbita/ponto 218/63 e data de passagem de 01/08/2016. As imagens passaram pelos seguintes procedimentos: conversão geométrica; conversão dos níveis de cinza da imagem (NC) para radiância espectral; conversão dos valores de radiância para refletância; correção por pixel em todas as cenas; correção atmosférica.

Dessa forma, foi possível empregar a Equação 3, que considera a interferência do solo exposto nas imagens selecionadas, a partir do ajuste do índice de vegetação da diferença normalizada (NDVI), quando a superfície não está totalmente coberta pela vegetação (BORATTO; GOMIDE, 2013). Destaca-se que foi utilizado o valor de 0,5 para o fator de ajuste (L), posto que ocorra na área cobertura vegetal de densidade intermediaria, particularmente as diversas fisionomias de caatinga.

$$
S A V I=\frac{(N I R-R)}{(N I R+R+L)} *(1+L)
$$

Onde: $\quad$ SAVI = índice de vegetação ajustado ao solo; NIR = fluxo radiante no infravermelho próximo; $\mathrm{R}$ = fluxo radiante na região do vermelho visível; $\mathrm{L}=$ fator de ajuste do índice SAVI, nesse estudo assumiu o valor de 0,5 , que é aplicado à vegetação com densidade intermediaria.

O produto resultante do SAVI foi manuseado no SIG ArcGIS, onde foi efetivada a delimitação dos intervalos das classes para o SAVI (Tabela 5), através da extensão Spatial Analyst Tool e ferramenta Reclassify do ArcGIS.

Tabela 5: Intervalos, classes atribuídas e notas ao índice de vegetação ajustado ao solo (SAVI) da Sub-bacia Hidrográfica do rio Piracuruca.

\begin{tabular}{c|c|c}
\hline Intervalos do SAVI & Classes atribuídas & Notas \\
\hline 0,6 a 0,8 & Vegetação com alta atividade fotossintética & 1 \\
\hline 0,4 a 0,6 & Vegetação com média atividade fotossintética & 2 \\
\hline 0,2 a 0,4 & Vegetação com baixa atividade fotossintética & 3 \\
\hline 0,1 a 0,2 & Área urbana / Veg. com muito baixa atividade & 4 \\
\hline 0 a 0,1 & fotossintética & 5 \\
\hline$<0,1$ & Solo exposto & - \\
\hline
\end{tabular}

Fonte: Santos (2019). 


\section{Resultados e discussão}

A seguir são apresentados e discutidos os resultados encontrados a partir do uso de SIG e emprego de álgebra de mapas, para discussão das quatro variáveis ambientais e, posterior, integração a partir do índice de suscetibilidade biofísica a inundações (ISBioI) para a Sub-bacia Hidrográfica do rio Piracuruca.

\section{Permeabilidade litológica $(L)$}

As formações geológicas e, respectiva, composição litológica da área estudada lhe conferem resistências distintas no que diz respeito à atuação de processos erosivos, onde se destacam as rochas magmáticas pertencentes à Formação Sardinha. Dessa forma, conforme está exposto na Figura 3, pode-se afirmar que a área em estudo exibe permeabilidade litológica diferenciada, com predominância de permeabilidade alta, que ocorre em 58,8\% de sua área, que está associado às Formações Serra Grande e Cabeças, ambas de constituição arenítica e com espessura entre o médio e o grosseiro (BRASIL, 1973), planos de diaclasamento e estratificação (PENTEADO, 1983). Desse modo, tais rochas encontram-se mais propenssas ao processo de infiltração que ao de escoamento superficial, dessa forma, logo baixa probabilidade a ocorrência de inundações.

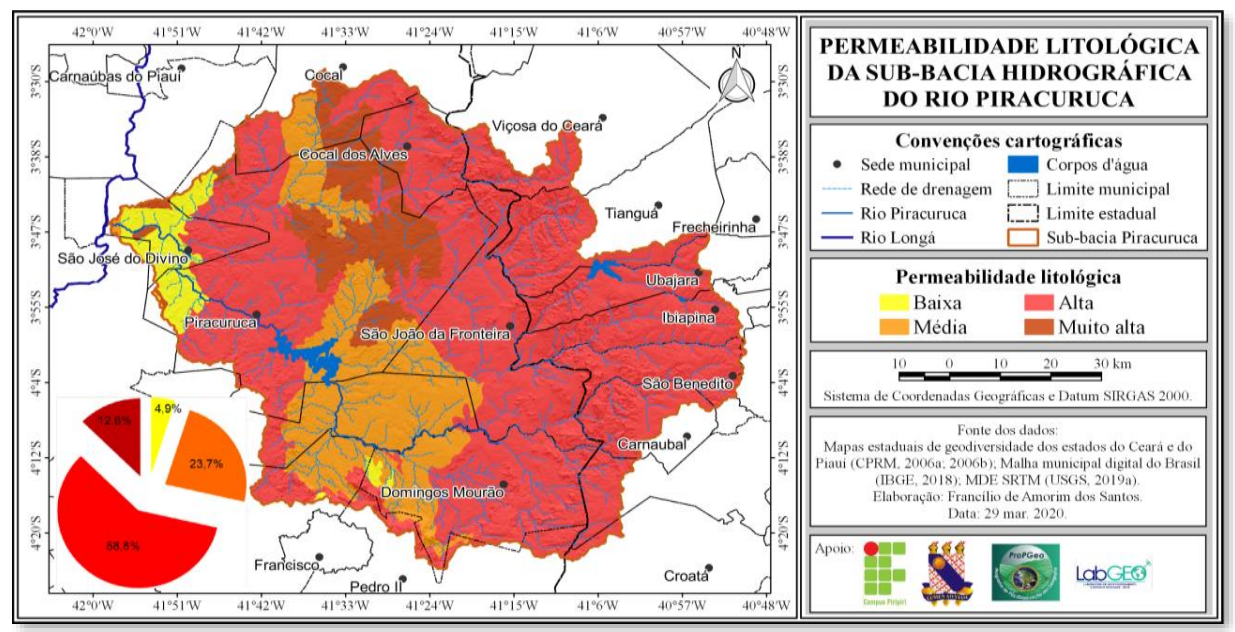

Figura 3: Permeabilidade litológica (L) da Sub-bacia Hidrográfica do rio Piracuruca. Fonte: Santos (2019). 
A classe de permeabilidade média, que ocorre por $23,7 \%$ da Sub-bacia, está associada aos folhelhos com intercalações de arenitos e siltitos da Formação Pimenteiras (BRASIL, 1973), que apresentam baixa permeabilidade, justificado pela sua granulação fina, origem sedimentar detrítica e a presença de fissilidade (PENTEADO, 1983), sendo, mais suscetíveis ao escoamento superficial que os arenitos e com maior probabilidade às inundações.

Por sua vez, a permeabilidade muito alta distribui-se por 12,6\% da Sub-bacia e atrela-se aos sedimentos arenosos, areno-argilosos e conglomeráticos (CPRM, 2006c), apresentam partículas granulometricamente grandes, incoesas e de fácil remoção, logo alto potencial de permeabilidade, infiltração da água e baixo potencial à ocorrência de inundações. Por seu turno, a permeabilidade baixa encontra-se por $4,9 \%$ da área pesquisada e está vinculada aos basaltos e diabásios da formação Sardinha, que possuem sua elevada coerência e pouca plasticidade (PENTEADO, 1983), gerando maior escoamento superficial, que resulta em alta probabilidade à ocorrência de inundações, onde está inserida a sede do município de São José do Divino.

\section{Declividade média do relevo (Dm)}

O relevo dada Sub-bacia do rio Piracuruca passa por processos erosivos, particularmente as bordas do planalto da Ibiapaba, que resulta na formação de áreas tabulares, pedimentos e de acumulação, essa última encontrada, principalmente, na parte central da Sub-bacia. Essa paisagem é típica de áreas semiáridas, de acordo com Penteado (1983), cujos detritos produzidos que ocupam as áreas rebaixadas e são provenientes das vertentes do referido Planalto, que são mantidas por arenito e são transportados pelo escoamento difuso, lençol d'água e vento.

$\mathrm{Na}$ Figura 4, que apresenta as classes de declividade, pode-se perceber a presença de áreas rebaixadas, particularmente associada ao relevo plano (0 a 3\%), que foi identificado em 58,4\% da área e ocorre, principalmente, na parte Centro-Oeste. O segundo tipo de relevo mais representativo está ligado à classe de declividade suave ondulada ( 3 a $8 \%$ ), distribuída por $28,3 \%$ da Sub-bacia, particularmente no trecho Centro-Leste, na transição da borda do planalto para as áreas rebaixadas. Por sua vez, encontra-se por $13,1 \%$ da área estudada relevo ondulado (8 a 20\%) e forte ondulado (20 a 45\%). 


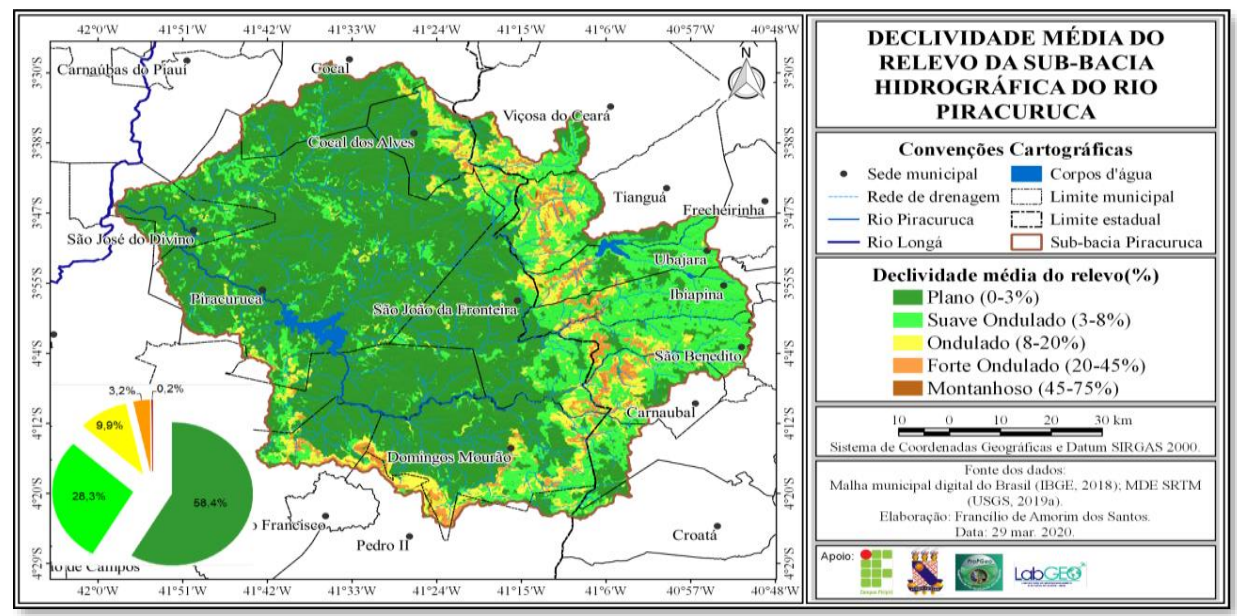

Figura 4: Declividade média do relevo (Dm) da Sub-bacia Hidrográfica do rio Piracuruca. Fonte: Santos (2019).

Reitera-se, ainda, que em $0,2 \%$ relevo montanhoso (45 a $75 \%$ ), localizado principalmente nas bordas do planalto da Ibiapaba. Esse tipo de relevo, de acordo com Código Florestal (BRASIL, 2012), é considerado uma área de preservação permanente (APP), principalmente devido à presença de relevo íngreme e de algumas nascentes do rio Piracuruca, fato que justifica sua preservação.

Em suma, infere-se que as áreas de menor declividade apresentam correlação com aquelas de mais rigorosas condições climáticas, rede de drenagem intermitente, solos mais rasos e incoesos. Nesse sentido, observa-se que os cinco municípios piauienses apresentam alta a muito alta suscetibilidade à ocorrência de inundações, posto que se situem em áreas planas, com destaque para Piracuruca e São José do Divino, que se encontram no baixo curso do rio Piracuruca.

\section{Índice de circularidade (Ic) das microbacias}

A divisão da Sub-bacia Hidrográfica do rio Piracuruca em microbacias (MB) foi essencial para estimar o potencial e a contribuição de cada uma delas para causar inundações na Sub-bacia como um todo. Desse modo, têm-se as seguintes microbacias: MB do rio Jacareí $\left(23 \%-1.770,2 \mathrm{~km}^{2}\right)$, MB do rio Catarina $\left(13,8 \%-1.060 \mathrm{~km}^{2}\right)$, MB do rio Pejuaba $\left(17,7 \%-1.367,3 \mathrm{~km}^{2}\right)$, MB do rio Arabé $\left(31 \%-2.389,4 \mathrm{~km}^{2}\right)$ e MB do rio Piracuruca $\left(14,5 \%-1.117,1 \mathrm{~km}^{2}\right)$, conforme se pode observar na Figura 5.

De acordo com o índice de circularidade (Ic) pode-se constar que todas as microbacias exibem forma alongada e baixa probabilidade à ocorrência de inundações rápidas, com destaca-se para a microbacia do rio Catarina que apresentou Ic de 0,35. Segue-se a essa microbacia a do rio Arabé (Ic de 0,31 ), do rio Jacareí (Ic de 0,29 ), do rio Pejuaba (Ic igual a 0,28) e do rio Piracuruca (Ic de 0,25). Embora a Sub-bacia do rio 
Piracuruca tenha baixa probabilidade à ocorrência de inundações, Ic de 0,35 , deve-se levar em conta a integração dos demais fatores ambientais para entendimento, de forma sistêmica, da suscetibilidade a inundações na Sub-bacia estudada.

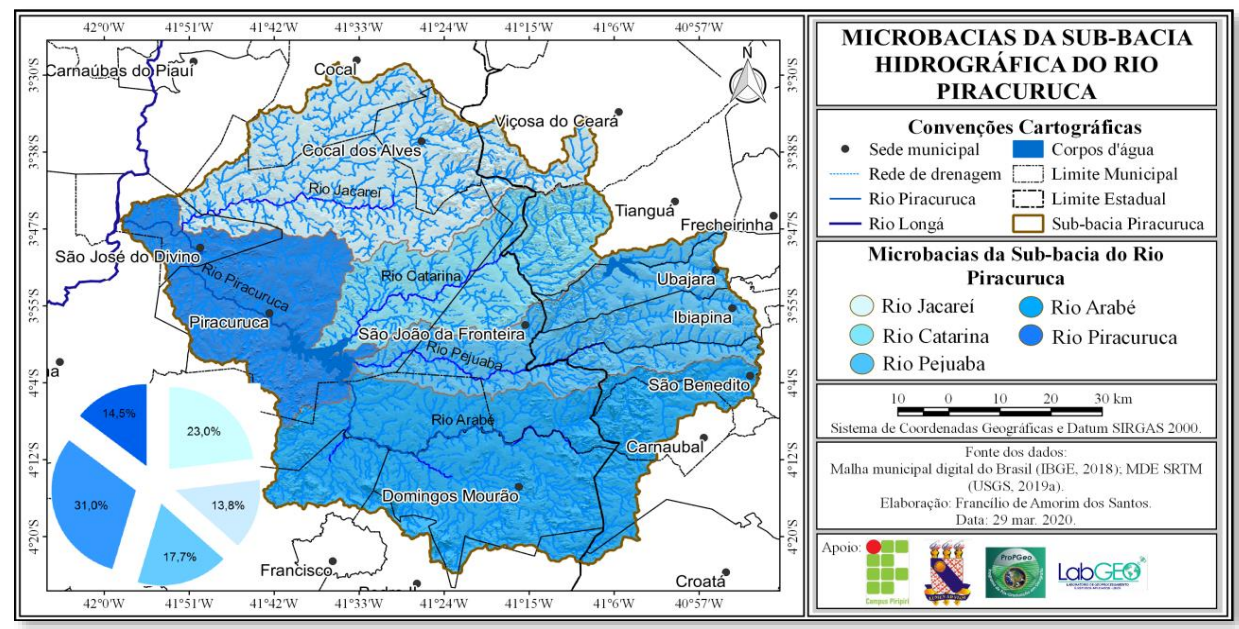

Figura 5. Índice de circularidade (Ic) das Microbacias que compõem a Sub-bacia Hidrográfica do rio Piracuruca.

Fonte: Santos (2019).

\section{Índice de vegetação ajustado ao solo (SAVI)}

Inicialmente, é relevante destacar que na Sub-bacia do rio Piracuruca os fatores edáficos são preponderantes para o desenvolvimento de uma distinta diversidade florística, posto que se tenha vegetação de grande porte (mata plúvio-nebular) e variações fisionômicas no que diz respeito à caatinga. Desse modo, por meio da Figura 6 observa-se que em $49 \%$ da Sub-bacia predomina vegetação com baixa atividade fotossintética, principalmente no setor Centro-Leste, na transição da borda do planalto para as áreas rebaixadas, onde se localizam as sedes dos municípios piauienses de Domingos Mourão e São João da Fronteira.

Ressalta-se que a segunda classe de fisionomia mais representativa diz respeito àquela de atividade fotossintética média, que ocorre por 40,9\% da área estudada, principalmente na parte Oeste. Por sua vez, a área urbanizada e com vegetação de muito baixa atividade fotossintética distribui-se por 8,7\% da Sub-bacia e está situada na parte cearense da Sub-bacia. As demais classes alta atividade fotossintética, corpos hídricos e solo exposto ocorrem por $1,1 \%, 0,3 \%$ e $0,1 \%$ da área estudada, respectivamente. 


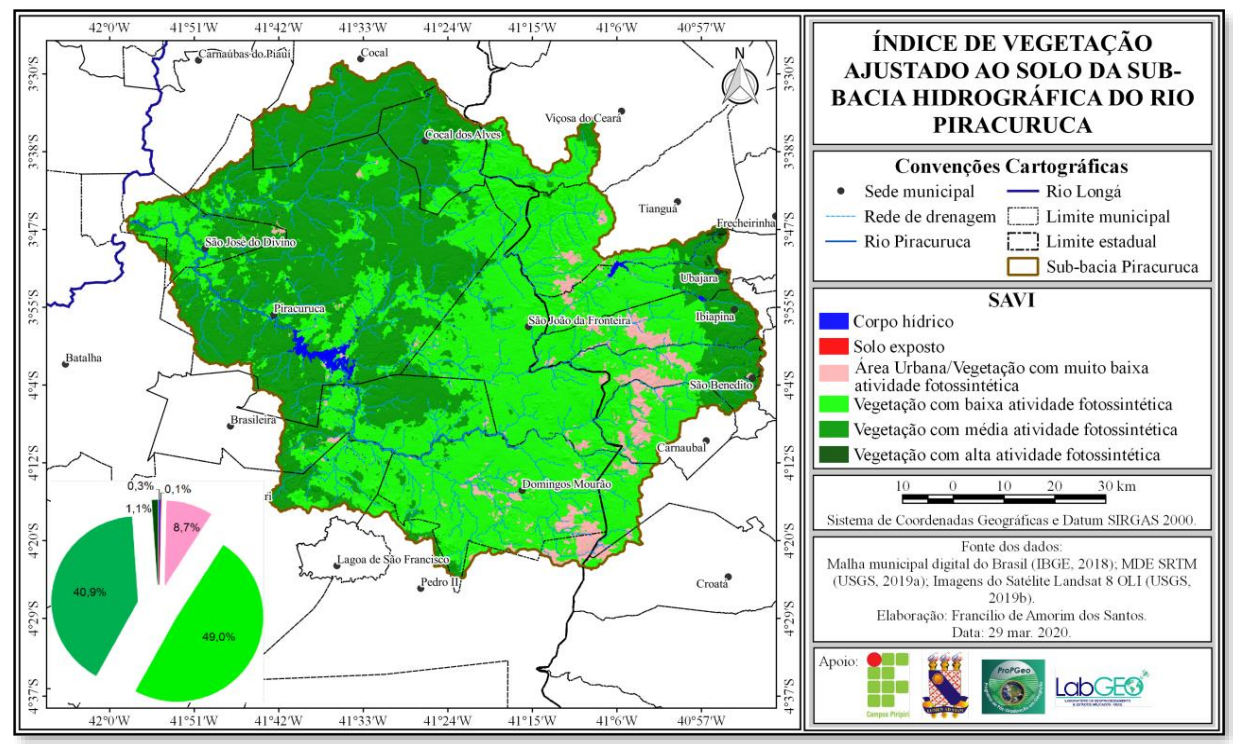

Figura 6: Índice de vegetação ajustado ao solo (SAVI) da Sub-bacia Hidrográfica do rio Piracuruca.

Fonte: Santos (2019).

Diante do que foi apresentado e tomando como base a relevância da cobertura vegetal como atenuadora dos processos inundatórios, ao reduzir o potencial cinético das gotas de chuvas, a velocidade do escoamento superficial, entre outros. Desse modo, observa-se que a área central da Sub-bacia do rio Piracuruca exibe maior probabilidade a inundações, visto que exibe vegetação esparsada e que está associada a relevo plano e solos rasos e mal drenados.

\section{Índice de suscetibilidade biofísica a inundações (ISBioI)}

Por meio da álgebra de mapas em SIG, que considerou as variáveis analisadas acima, foi possível, a construção do índice de suscetibilidade biofísica a inundações (ISBio I), foi possível estimar as áreas mais suscetíveis a ocorrência de inundações na Subbacia do rio Piracuruca, conforme está exposto na Figura 7. Nessa visualiza-se a preponderância de suscetibilidade média a inundações, que ocorre por $59,5 \%$ da Subbacia, distribuindo-se por toda a área estudada e está ligada, principalmente, a alta permeabilidade litológica, relevo plano e vegetação esparsada. 


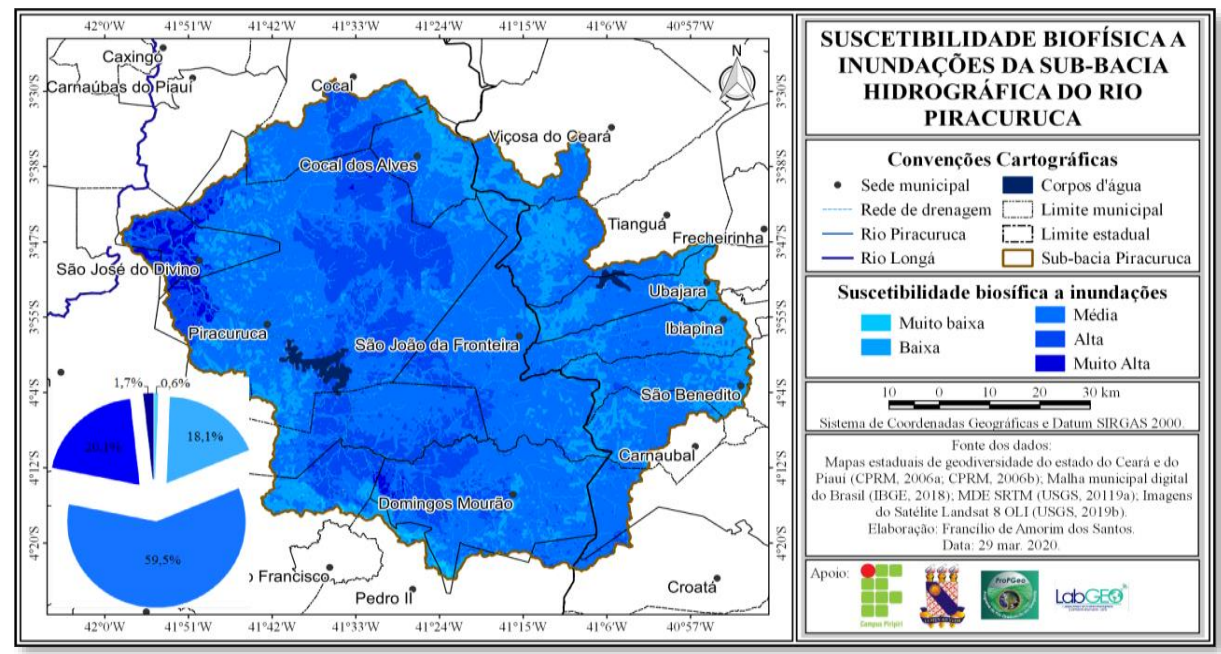

Figura 7: Índice de suscetibilidade biofísica a inundações (ISBioi) da Sub-bacia Hidrográfica do rio Piracuruca.

Fonte: Santos (2019).

Por sua vez, em $21,8 \%$ da Sub-bacia ocorre alta a muito alta suscetibilidade biofísica a inundações, localizada na parte central e baixo curso, onde se situa a sede do município de São José do Divino, estando associada a presença de litologia magmática e relevo plano. Por seu turno, $18,7 \%$ da Sub-bacia está assentada sobre área de muito baixa a baixa suscetibilidade a inundações, cuja localização diz respeito às bordas da Sub-bacia, onde se tem a presença de média a alta permeabilidade litológica, relevo íngreme e vegetação de alta atividade fotossintética, onde se sobressam os três municípios cearenses.

\section{Conclusões}

O estudo foi de suma importância para o reconhecimento das áreas com maior suscetibilidade biofísica a inundações da Sub-bacia Hidrográfica do rio Piracuruca. Desse modo, cabe salientar que o método e a técnica aplicada foram eficientes para alcançar o objetivo proposto no estudo. Ressalta-se, também, que foi possível a compreensão do potencial e da contribuição que cada indicador ambiental eixe para construção da suscetibilidade biofísica da área a processos inundatórios.

Dessa forma, inferiu-se que na Sub-bacia do rio Piracuruca predomina: permeabilidade alta, com ocorrência em 58,8\% de sua área, particularmente devido a sua constituição arenítica; relevo com declividade plana (0 a 3\%), identificado em 58,4\%; microbacias com forma alongada e índice de circularidade para a Sub-bacia do rio Piracuruca $\leq 0,35$, que representa baixa probabilidade a inundações rápidas; vegetação com baixa atividade fotossintética, encontrada em $49 \%$ da Sub-bacia. 
A integração dessas variáveis por meio do índice de suscetibilidade biofísica a inundações (ISBio ${ }_{I}$ ) possibilitou estimar que na Sub-bacia do rio Piracuruca prevalece suscetibilidade média a inundações, cuja ocorrência dá-se por 59,5\% de sua área, justificandose pela ocorrência de média a alta permeabilidade litológica, relevo plano e vegetação esparsada. Dessa maneira, evidencia-se a necessidade de estudos posteriores para conhecimento da vulnerabilidade da população situada, particularmente, nessa área de média suscetibilidade e criação de estratégias para convivência com as inundações.

\section{Referências}

AYOADE, J. O. Introdução à climatologia para os tópicos. Tradução de Maria Juraci Zani dos Santos; revisão de Suely Bastos; coordenação editorial de Antonio Christofoletti. 6. ed. Rio de Janeiro: Bertrand Brasil, 2001. 332p.

BORATTO, I. M. P.; GOMIDE, R. L. Aplicação dos índices de vegetação NDVI, SAVI e IAF na caracterização da cobertura vegetativa da região Norte de Minas Gerais. In: SIMPÓSIO BRASILEIRO DE SENSORIAMENTO REMOTO, 16., 2013, Foz do Iguaçu. Anais... Foz do Iguaçu: SBSR, 2013, p.7.345-7.352.

BRASIL. Ministério da Integração Nacional. Secretaria Nacional de Defesa Civil. Centro de Nacional de Gerenciamento de Riscos e Desastres. Anuário brasileiro de desastres naturais: 2013. - Brasília: CENAD, 2014.

BRASIL. Ministério de Minas e Energias. Departamento Nacional de Produção Mineral. Projeto RADAM: levantamento dos recursos naturais, v.02, Folha SB. 23 / 24 - Teresina / Jaguaribe; geologia, geomorfologia, solos, vegetação e uso potencial da terra. Rio de Janeiro, 1973.

BRASIL. Novo Código Florestal. Lei $n^{\circ} 12.651$, de 25 de maio de 2012. Dispõe sobre a proteção da vegetação nativa; altera as Leis ${ }^{\text {os }} 6.938$, de 31 de agosto de 1981, 9.393, de 19 de dezembro de 1996, e 11.428, de 22 de dezembro de 2006; revoga as Lei ${ }^{\text {os }} 4.771$, de 15 de setembro de 1965, e 7.754, de 14 de abril de 1989, e a Medida Provisória no 2.166- 67, de 24 de agosto de 2001; e dá outras providências. 2012.

CAMARGO, L. H. R. A Geoestratégia da Natureza: a Geografia da Complexidade e a Resistência à possível Mudança do Padrão Ambiental Planetário. Rio de Janeiro: Bertrand Brasil, 2012. 240p.

CARDOSO, J. A. Aspectos físicos e conflitos decorrentes do uso das terras da microbacia do riacho do Roncador em Timon (MA). 2013. 170f. Dissertação (Mestrado em Geografia) - Universidade Federal do Piauí. Teresina, 2013.

CPRM - SERVIÇO GEOLÓGICO DO BRASIL. Ministério de Minas e Energia. Mapas estaduais de geodiversidade: Ceará. Rio de Janeiro: CPRM. 2006a. Documento cartográfico em arquivo vetorial. Disponível em 〈http://geobank.sa.cprm.gov.br〉. Acesso em: 14 jan. 2014. 
CPRM - SERVIÇO GEOLÓGICO DO BRASIL. Mapas estaduais de geodiversidade: Piauí. Rio de Janeiro: CPRM. 2006b. Documento cartográfico em arquivo vetorial. Disponível em <http://geobank.sa.cprm.gov.br>. Acesso em: 14 jan. 2014.

CPRM - SERVIÇO GEOLÓGICO DO BRASIL. Mapa Geológico do Estado do Piauí. $2^{a}$ Versão. Teresina, 2006c.

EMPRESA BRASILEIRA DE PESQUISA AGROPECUÁRIA. Centro Nacional de Pesquisa de Solos (Rio de Janeiro, RJ). Sistema brasileiro de classificação de solos. Rio de Janeiro: EMBRAPA-SPI, 2009.

FERREIRA, A. G.; MELLO, N. G. S. Principais sistemas atmosféricos atuantes sobre a região Nordeste do Brasil e a influência dos Oceanos Pacífico e Atlântico no clima da região. Revista Brasileira de Climatologia, Curitiba, v.1, n.1, p.15-28, dez. 2005.

FUNCEME - FUNDAÇÃO CEARENSE DE METEOROLOGIA E RECURSOS HÍDRICOS. Sistemas Meteorológicos Causadores de Chuva na Região Nordeste do Brasil. Disponível em:

<http://www.funceme.br/produtos/script/chuvas/Grafico_chuvas_postos_pluviometricos/ entender/entender2.htm>. Acesso em: 06 fev. 2019a.

FUNCEME - FUNDAÇÃO CEARENSE DE METEOROLOGIA E RECURSOS HÍDRICOS. O Dipolo de Temperatura de Superfície do Mar (TSM) do Atlântico Tropical. Disponível em:

<http://www.funceme.br/produtos/manual/oceanografia/Campos_TSM/dipolo.htm>. Acesso em: 06 fev. 2019b.

IBGE - INSTITUTO BRASILEIRO DE GEOGRAFIA E ESTATÍSTICA. Malha municipal digital do Brasil: situação em 2018. Rio de Janeiro: IBGE, 2014. Disponível em: <ftp://geoftp.ibge.gov.br/malhas_digitais/>. Acesso em: 04 dez. 2019.

INDE - INFRAESTRUTURA NACIONAL DE DADOS ESPECIAIS. Mapa de Solos da Folha SB.24 - Jaguaribe. Disponível em: 〈http://www.visualizador.inde.gov.br/〉. 2014. Acesso em: 13 set. 2018.

LISTO, F. L. R. Análise da suscetibilidade e do grau de risco a escorregamentos rasos na Bacia do Alto Aricanduva, RMSP (SP). 2011. 151f. Dissertação (Mestrado em Geografia) - Universidade de São Paulo. São Paulo, 2011.

MOLION, L. C. B.; BERNARDO, S. O. Dinâmica das Chuvas no Nordeste Brasileiro. In: CONGRESSO BRASILEIRO DE METEOROLOGIA, 11., 2000, Rio de Janeiro. Anais... Rio de Janeiro: 2000, p.1.334-1.342.

MONTEIRO, J. B.; PINHEIRO, D. R. C. O desastre natural como fenômeno induzido pela sociedade: abordagens teóricas e metodologias operacionais para identificação/mitigação de desastres naturais. Revista de Geografia, Juiz de Fora, v.2, n.1, 2012. 
NATIONAL AERONAUTICS AND SPACE ADMINISTRATION. Landsat Science. Disponível em: <https://landsat.gsfc.nasa.gov/landsat-8/landsat-8-bands/>. Acesso em: 23 jan. 2019.

PENTEADO, M. M. Fundamentos de geomorfologia. 3. ed. Rio de Janeiro: Fundação IBGE, 1983. 185p.

PINHEIRO, R. A. B. Análise do processo de degradação/desertificação na bacia do Riacho Feiticeiro, com base no DFC, município de Jaguaribe-Ceará. 129f. Dissertação (Mestrado em Desenvolvimento e Meio Ambiente) - Universidade Federal do Ceará. Fortaleza, 2011.

SANTOS, F. A. Resiliência ambiental a secas e a inundações na Sub-bacia Hidrográfica do rio Piracuruca (CE-PI). 268p. Tese (Doutorado em Geografia) Universidade Estadual do Ceará, Centro de Ciências e Tecnologia, Programa de PósGraduação em Geografia, Fortaleza, 2019.

SCHUMM, S. A. Evolution of drainage systems and slopes in badlands of Perth Amboy. Geological Society of America Bulletin, New York, v.67, n.5, p.597-646, May. 1956.

SILVA, T. F.; PAIVA, A. L. R.; SANTOS, S. M. Análise estatística e tendência das precipitações no município de Caruaru - PE. In: SIMPÓSIO BRASILEIRO DE RECURSOS HÍDRICOS, 21., 2015, Brasília. Anais... Brasília: SBRH, 2015.

TOMINAGA, L. K.; SANTORO, J.; AMARAL, R. (Organizadores). Desastres naturais: conhecer para prevenir. São Paulo: Instituto Geológico, 2009. 196p.

UNITED STATES GEOLOGICAL SERVICE (Serviço Geológico dos Estados Unidos). Earth Explorer. Digital Elevation: SRTM 1 Arc-Second Global. 2017. Disponível em: <http://earthexplorer.usgs.gov/>. Acesso em: 23 nov. 2019a.

UNITED STATES GEOLOGICAL SERVICE (Serviço Geológico dos Estados Unidos). Earth Explorer. Collection: Landsat Archive. Disponível em: <http://earthexplorer.usgs.gov/>. Acesso em: 23 nov. $2019 \mathrm{~b}$.

VAREJÃO-SILVA, M. A. Meteorologia e Climatologia. Versão Digital 2. Recife, 2006. 449p.

VALOR, E.; CASELLES, V. Mapping Land Surface Emissivity from NDVI: Application to European, African, and South American Areas. Remote Sensing of Environment, v.57, p.167-184, 1996.

XAVIER, T.M.B.S. "Tempo de Chuva”: estudos climáticos e de previsão para o Ceará e Nordeste setentrional. Fortaleza: ABC Editora, 2001. 478p. 
Francílio de Amorim dos Santos

Doutor e Pós-Doutor em Geografia pela Universidade Estadual do Ceará; Mestre em Geografia pela Universidade Federal do Piauí; Graduado em Geografia pela Universidade Estadual do Piauí; Graduado em Ciências Biológicas pelo Instituto Federal do Piaú́.

Instituto Federal do Piauí / Campus Piripiri, Av. Rio dos Matos, S/N, Bairro Germano. CEP: 64.260-000. Piripiri - PI.

E-Mail: francilio.amorim@ifpi.edu.br

\section{Lúcia Maria Silveira Mendes}

Doutora em Agronomia pela Universidade de São Paulo; Mestre em Agronomia pela Universidade Federal do Ceará; Graduada em Agronomia pela Universidade Federal do Ceará.

Universidade Estadual do Ceará / Campus do Itaperi, Av. Dr. Silas Munguba, 1700, CEP: 60.714.903.

E-mail: lucia.mendes@uece.br.

\section{Maria Lúcia Brito da Cruz}

Pós-Doutora em Geografia pela Universidade Federal do Pará; Doutora em Geografia pela Universidade Federal de Pernambuco; Mestre em Desenvolvimento e Meio Ambiente pela Universidade Federal do Ceará; Graduada em Geografia pela Universidade Estadual do Ceará.

Universidade Estadual do Ceará / Campus do Itaperi, Av. Dr. Silas Munguba, 1700, CEP: 60.714.903.

E-mail: mlbcruz@gmail.com. 